\title{
BREASTFEEDING IN CRISIS: SURVEY RESULTS OF THE BABY-FRIENDLY HOSPITAL INITIATIVE
}

\author{
C Nikodem, L Schelke, L Enraght-Moony and GJ Hofmeyr
}

\begin{abstract}
Objective To assess current breastfeeding practices in hospitals in South Africa.

Design : Survey conducted by means of a postal questionndire for hospitals and a questionnatre based on the baby-friendly initiative action folder for mothers.
\end{abstract}

Setting : All private and provincial hospitals according to the 1992 address ltst supplied by the Department of National Health: Readers of "Living and Loving" and breastfeeding liaison groups.

Main outcome measure:

The levet of implementation of the "Ten Steps ta Successfut Breastfeeding"

Results - Less than half of the responding hospitals reported having a written breastfeeding policy. Most hospitats have a shortage of specialized training in the support of breastfeeding. This is consistent with the outcome of the maternat questionnaire indicating that the average hospital is not baby friendly.

Conclusions : A concerted effort should be made by hospitals to implement the "Ten Steps to Successful Breastfeeding" and attention should be given to building breastfeeding skills into the curriculum for medical students, nurses and allied disciplines as well as in-service training for current health care workers.

\section{INTRODUCTION}

In 1989 a joint statement, entitled "Protecting, Promoting and Supporting Breastfeeding: The special role of maternity services", was published by the World Health Organisation (WHO) and the United Nations Children's Fund (UNICEF). The aim of this statement was to increase awareness of the critical role of health services in the promotion of breastfeeding and to give guidelines for appropriate information and support to mothers. In this statement, the "Ten Steps to Successful Breastfeeding" was introduced.

This was followed by the Innocenti Declaration on the protection, promotion and support of breastfeeding which was adopted by 32 governments at a meeting held under the auspices of the WHO and UNICEF in August 1990 (WHO/UNICEF 1990). The following was declared as a global goal for optimal maternal and child health and nutrition

All women should be enabled to practise exclusive breastfeeding

All infants should be fed exclusively on breastmilk from birth to four 10 six months of age.

To attain this goal, it was further stated that "Efforts should be made to increase women's confidence in their ability to breastfeed. Such empowerment involves the removal of constraints and influences that manipulate perceptions and behaviour towards breastfeeding. often by subtle and indirect means... obstacles to breastfeeding within the health system, the workplace and the community must be eliminated."

One of the operational targets set by the Innocenti Declaration was that all governments by the year 1995 should have "ensured that every facility providing maternity services fully practises all ten of the Ten Steps to Successful Breastfeeding set out in the joint WHO/UNICEF statement..."

In 1990, the Committee for Health Matters that was the former South African statutory health policy-making body - adopted a slightly amended version of the Ten Steps to Successful Breastfeeding as the official national breastfeeding policy for South Africa
Currently the Baby-Friendly Hospital Initiative is being implemented world-wide under the auspices of UNICEF. The National Alliance for Breastfeeding Action and the Witwatersrand Breastfeeding Liaison Group have committed themselves to participate in this initiative, inter alia by conducting this assessment of the state of "baby-friendliness" of South African hospitals. A baby-friendly hospital is one that fully practises the Ten Steps to Successful Breastfeeding, and only may call itself baby friendly after international assessment. St Monica's Maternity Home, Cape Town, received the first Baby-Friendly Hospital Award in South Africa during June 1994.

\section{OBJECTIVE}

The main objective of the study was to determine the degree of implementation of the "Ten Steps to Successful Breastfeeding" in South African hospitals.

\section{STUDY DESIGN and METHODS}

A postal questionnaire based on the UNICEF Self-Appraisal Questionnaire was sent to 330 hospitals in the former four provinces of South Africa. Addresses were obtained from the 1992 Hospital and Nursing Yearbook, supplied by Department of National Health.

The questionnaires were anonymous and confidential and were addressed to the medical superintendent. A covering letter providing permission from the appropriate provincial authorities accompanied the questionnaires. $A$ self-addressed envelope was enclosed to facilitate return of the questionnaires. It was requested that the questionnaire be completed by marking the applicable blocks and returned by 28 February 1993. A reminder letter was sent out two weeks after the expiry date.

To complement the self-evaluation questionnaire for the hospitals, a questionnaire based on the baby-friendly initiative action folder (World Alliance for Breastfeeding Action) for mothers was published in the magazine "Living and Loving" and mothers were invited to report on their experiences. It was also distributed to breastfeeding liaison groups. The main goal was to evaluate the hospital services experienced by mothers at their local hospitals. Seventeen questions were 
developed, covering the Ten Steps to Successful Breastfeeding. The highest score that could be obtained was eighteen, with scores being grouped into four categories:

\section{$17-18$ points.}

Congratulations! Your facility is doing a wonderful job in protecting, supporting and promoting breastfeeding.

\section{$15-16$ points.}

Keep up the good work! You are effectively helping breastfeeding mothers and babies. Find out how you can be even more helpful by contacting one of the sponsoring organizations.

\section{$13-14$ points.}

Your facility could do much more to assis breastfeeding. The sponsoring organizations have technical assistance available for suggestions on how to implement the Ten Steps.

\section{$0-12$ point:}

Breastfeeding mothers and babies are having a difficult time at your facility. Find out why these issues are important so you can begin to make changes immediately that will increase the satisfaction of your patients and improve infant health.

Permission was obtained from the committee for research on human subjects of the University of the Witwatersrand, Steering Committee for National Breastfeeding Week (now, National Alliance for Breastfeeding Action) and from the four provincial authorities.

\section{RESULTS}

The response rate of the hospital questionnaires was $42 \%(138 / 330)$. The low reponse rate was a matter of concern and it is recognised that this could have an influence on the results. A total of 516 questionnaires was received from mothers, 311 in reponse to the publication in "Living and Loving" and 205 from breastfeeding liason groups.

\section{Step 1 Have a written breast-feeding} policy that is routinely communicated to all health care staff.

Only $47 \%$ of the hospital respondents said that they had an explicit written policy for protecting, promoting and supporting breastfeeding. Of these, only $57 \%$ prohibit al promotion of, and group instruction for the use of breast-milk substitutes, bottles and teats in their policy. Although $64 \%$ had the policy displayed in all working areas, only $35 \%$ had a mechanism for evaluating the effectiveness of the policy.

Only $17 \%$ of mothers were aware that the hospital where they delivered had a written breast-feeding policy which reflected the "Ten Steps".

Step 2 Train all health care staff in skills necessary to implement this policy.

Most (98\%) hospitals which had a written policy responded that all staff were aware of and acquainted with the policy. Very few had arranged for specialised training in lactation management of specific staff members (15\%).

Seventy five percent of mothers who responded felt that staff were knowlegdeable and supportive of breast-feeding.

\section{Step 3 Inform all pregnant women about the benefits and management of breastfeeding.}

Although $71 \%$ of the hospitals indicated that the mother's antenatal record was available at the time of delivery, only $42 \%$ responded that the antenatal record reflected whether breastfeeding had been discussed with the mother.

About half of the mothers responded that the benefits and management of breastfeeding had been discussed with them antenat ally.

Step 4 Help mothers initiate breastfeeding within half an hour of birth.

The majority (98\%) of hospitals allow mothers who had a vaginal delivery to hold their babies within half an hour of the completion of second stage. Most hospitals reported that mothers who had caesarean sections are given their infants to hold within half an hour after they are able to respond to their babies.

Only 44\% of mothers reported that they were given the opportunity to put their babies to the breast for the first time within one hour after delivery.

Step 5 Show mothers how to breastfeed, and how to maintain lactation even if they should be separated from their infants.

Less than half (43\%) of the hospitals responded that they have staff members who have specialised training in breastfeeding and lactation management available full-time to assist mothers. Seventy two percent responded that they help mothers of babies in special care to establish and maintain lactation by frequent expression of milk.

Two thirds (71\%) of mothers responded that they were shown how to breastfeed their infants.

\section{Step 6 Give newborn infants no milk} feeds or water other than breastmilk, unless indicated for a medical reason.

Although $76 \%$ of hospitals responded that staff members have a clear understanding of what the few acceptable reasons are for prescribing food or drink other than breastmilk for breastfeeding babies, $60 \%$ still give routine supplementation of water, glucose or formula Very few $(12 \%)$ hospitals still receive free or low-cost supplies of breastmilk substitutes.

Fifty-three percent of mothers were aware that their breastfed infants received other foods or drinks while in hospital.

Step 7 Allow mothers and infants to remain together 24 hours a day from birth.

Although the majority (78\%) of hospitals allow rooming-in, only half commence rooming-in within 1 hour for normal deliveries and within 3-6 hours for caesarean sections.

Only $41 \%$ of mothers responded that their babies remained with them at all times during their stay at the hospital.

\section{Step 8 Encourage natural breastfeeding} frequently and on demand.

Step 9 Do not give, or encourage, the use of artificial teats or dummies to breastfed infants. Do not encourage the use of nipple shields either.

In $64 \%$ of the hospitals, mothers were advised to feed their babies on need. Although the majority $(84 \%)$ of hospitals did advise mothers to avoid bottles and dummies, half of them (50\%) still gave bottles, and fewer (37\%) gave dummies.

Less than half of the mothers responded that they received advice to feed their infants on need. Forty one percent of mothers received artificial teats or dummies while in hospital.

\section{Step 10 Promote the establisment of breastfeeding support groups and refer mothers to these on discharge from the hospital or clinic.}

Very few hospitals (11\%) were involved in the formation of support groups for breastfeeding mothers and fewer than half of the hospitals reported that they referred mothers to available support groups or had a system of follow-up for breastfeeding at the postnatal clinic. Only half of the respondents would allow trained counsellors of breastfeeding organisations to support mothers in their maternity services

Twenty eight percent of the mothers responded that they were told where to contact a breastfeeding support group when they were discharged from hospital.

Overall, most hospitals $(78 \%)$ rated their breastfeeding practices as good. Mothers did not feel the same and only $50 \%$ responded that their breastfeeding experience was improved by the facility. The mean total score was nine points (Standard error of measurement 0,19) which falls within the last category of 0 to 12 points: Breastfeeding mothers and babies are having a difficult time at your facility. 
Find out why these issues are important so you can begin to make changes immediately that will increase the satisfaction of your patients and improve infant health.

The main comments made by mothers were to express their disappointment in the lack of supporh, restriction of feeding, reduction of self-esteem by the patronising approach of health care workers, and the conflicting advice received from professionals.

\section{DISCUSSION}

In several countries, studies of the promotion of breastfeeding by changing hospital policies and practices have been undertaken. The training of health care workers should be especially considered, as they play a central role in providing support and prolonging the duration of breastfeeding (Iker \& Mogan 1992).

Referring to the current study, although most responding hospitals rated their breastfeeding practices as good, the results indicate that a lack of specialised training in the support of breastfeeding exists in current hospital practices. It is possible that the hospitals which responded would tend to be those with more progressive breastfeeding policies. The outcome of the maternal questionnaire is consistent with these results as the mean total score of nine points falls into the lowest category, indicating that the average hospital is not baby-friendly.

The World Health Organization has accepted that the vast majority of women ( $97 \%$ or more) are physiologically capable of breastfeeding their babies successfully. Although breastfeeding is natural, it is not an instinct but an acquired skill that must be practised. Correct positioning and attachment of the baby at the breast is important in preventing sore nipples and in successfully establishing lactation Rigard \& Alade 1992). Health workers need to understand the underlying mechanisms of suckling and should acquire the necessary skills and experience to help mothers position their babies correctly.

As the benefits of early latching, suckling and skin-to-skin contact are known to enhance mother-child bonding and to prolong the duration of breastfeeding (Christensson et al 1992) the health worker should ensure that each mother receives skilled help at the first feed after delivery. The first feed should be within the recognised period of early responsiveness when the baby's rooting and suckling reflexes are particularly strong. Whilst acknowledging the benefits of early skin-to-skin contact, professionals should consider individual needs and cultural behaviour of the parturient mother and therefore not force early skin-to-skin contact on an unwilling mother, as this may lead to adverse reactions (Raphael - Leff 1991). Opportunity for such contact should be provided, with the benefits having been explained to the mother antenatally.
Most health care workers are aware that dummies or bottle teats, particulary in the first week of life, can lead to disturbed suckling patterns in babies (Victoria et al 1993), but results of this study show that that they do not advise against this practice. The favoun ing of rooming-in was reported by the majority of hospitals. When rooming-in and early initiation of breastfeeding are part of hospital policy, feeding on need is greatly facilitated. Rooming-in also provides an opportunity for the new mother to get to know her baby and to take responsibility for her baby's care before going home.

All women should be encouraged to practise exclusive breast-feeding from the time of birth to four to six months of age. Prelacteal feeds such as water, glucose, infant formula, ncumbe or any other fluids should be strongly discouraged as they may interfere with the successful establishment of lactation. Health care workers should be trained not to give any supplementary feeds to healthy full-term infants (Nylander et al 1991) unless medically indicated. Breastmilk is recommended whenever possible, even for preterm infants, although their feedings may be individually determined. (Meier \& Pugh 1985: Musoke 1990; Mathur et al 1990).

The WHO recommends that breast-feeding should continue to be promoted in all developing countries including those with high prevalence rates of HIV in women of child bearing age (WHO 1987; Lederman 1992: Goldfarb, 1993). However, recommmendations for HIV-positive mothers may be confusing as in certain industrialised countries artificial feeding is advised (Porcher, 1992). Alternative feeding should only be recommended wherever the risks of artificial feeding are found to be less than those of an HIV-positive mother transmitting the virus to her baby through breastfeeding. Families should be able to afford breastmilk substitutes and bottles, have a safe water supply and have received individual explanations on how to use and prepare artificial feeding (Gray et al 1994).

Research on factors related to success in exclusive breastfeeding demonstrate the importance of support, motivation and level of information about breastfeeding. While mothers who prefer to breastfeed make this decision early, women choosing to bottlefeed decide later in pregnancy.

This suggests that the provision of well-designed, written and illustrated information on breastfeeding and the physiology of lactation, early in pregnancy, may enable the mother to make an informed decision. Mothers who experience complicated labour, or who are young, poorly educated, of low income, or returning to school or work soon after delivery are at risk for breastfeeding failure(Gielen et al, 1991; Morrison et al, 1989). Educational programmes developed to achieve exclusive breastfeeding and increase the duration of breastfeeding should consider these demographic and attitudinal factors important in the decision whether to breast- or bottle-feed.

Generally, emotional support throughout pregnancy, labour and the postnatal period is closely linked to breastfeeding success. The provision of emotional support promotes a woman's self-confidence in her ability to produce sufficient milk and her belief in her competence as a mother. A lack of such self-confidence and doubt in mother's competence are common factors in early cessation of breastfeeding (Hofmeyr et al, 1991). The impact of antenatal education depends as much on given information as on offered support. Improving knowledge without simultaneously creating a positive attitude has been shown to be ineffective in changing existing behaviour or increasing the duration of breastfeeding. It is therefore necessary to identify the mother's perception of breastfeeding early in pregnancy so that support will take cognisance of her specific fears or concerns.

As breastfeeding is a process to be leamed by experience, postnatal reinforcement, continued after hospital discharge, will enable mothers to cope successfully with breastfeeding problems, and increase the rates of breastfeeding success. It is therefore recommended that all mothers be referred to professional or mother-to-mother breast-feeding support groups on discharge.

\section{LIMITATIONS}

One of the limiting factors of this study was the low response rate of hospitals. Whether this reflects hospital attitudes and values about the necessity of a breastfeeding policy needs further evaluation and should be taken into account when a follow-up study is considered. Our data demonstrated that the majority of hospitals either lacked a written policy or that the policy only partially complied with the recommended WHO/UNICEF policy.

A further limitation is that the mothers responses were self selected. It is possible that women who were unhappy with the care they received would be more likely to complete the questionnaire.

\section{RECOMMENDATIONS}

Curricula for medical students, nurses and allied disciphnes, as well as in-service training programmes for current health care workers, should be regularly updated on recent breastfeeding issues and practices. The provision of group and one-to-one antenatal breastfeeding counselling should improve attempts to ensure that every pregnant woman is able to make informed decisions on infant feeding.

Implementation of a uniform breastfeeding policy will improve congruent advice of health care workers thus preventing confusion in 
mothers, enhancing mothers' self-confidence, and elevating breastfeeding success.

Most hospitals in South African have been notified regarding the Ten Steps to Succesfull Breastfeeding. Guidelines to facilitate the implementation of the Ten Steps should be issued (Nikodem et al, 1994).

\section{ACKNOWLEDGEMENTS}

The National Alliance for Breastfeeding Action, Dr Anne-Marie Bergh, Sean Enraght-Moony, Dr. Metin Gülmezoglu and the Department of National Health.

\section{REFERENCES}

Christensson K, Siles C, Moreno L, Belaustequi A, De La Fuente P, Lagercrantz $H$, Puyol P \& Winberg J. (1992): Temperature, metabolic adaptation and crying in healthy full-term newborns cared for skin-to- skin or in a cot. Acta Paediatr 81:488-93.

Gielen AC, Faden RR, O'Campo P, Brown CH \& Paige DM, (1991): Maternal employment during the early postpartum period: effects on initiation and continuation of breastfeeding. Pediatrics 87:298-305.

Goldfarb J. (1993): Breastfeeding, AIDS and other infectious diseases. Clin Perinatol 20(1):225-43.

Gray G, Salojee H \& McIntyre J. (1989): Breastfeeding and HIV transmission. Guidelines AJDS Bulletin 1994 Vol.3, No.1.
Hofmeyr GJ, Nikodem VC, Wolman W-L Chalmers BE \& Kramer T (1991): Companionship to modify the clinical birth environment: effects on progress and perceptions of labour and breastfeeding. $\mathrm{Br} J$ Obstet Gyn 98:756-764.

Iker CE, Mogan J. Supplementation of breastfed infants (1992): does continuing education for nurses make a difference? $J$ Hum Lact 8(3):131-5.

Lederman SA, (1992): Estimating infant mortality from Human Immunodeficienty virus and other causes in breastfeeding and bottlefeeding populations. Pediatrics 89:290-296.

Mathur MB, Dwarkadas AM, Sharma VK, Saha K \& Jain N, (1990): Anti-infective factors in preterm human colostrum. Acta Paediatr Scand 79:1039-44.

Meler P \& Pugh EJ, (1985): Breastfeeding behavior of small preterm infants. $M C N$ 10:396-40.

Morrison J, Najman JM, Williams GM, Keeping JD \& Andersen MJ. (1989): Socio-economic status and pregnancy outcome. An Australian study. Br J Obstet Gyn 96:298-307.

Musoke RN. (1990): Breastfeeding promotion: Feeding the low birth weight infant. Int $J$ Gynecol Obstet 31(suppl. 1):57-59.

Nikodem C, Moony L, Bergh A \& Scheike L. (1994): Guidelines to implementation of the Ten Steps to Successful Breastfeeding. Johannesburg:In press

Nylander $G$, Lindemann $R$, Helsing $E$ \& Bendrold E. (1991): Unsupplemented breastfeeding in the matemity ward. Postive long-term effects. Acta Obstet Gynecol Scand 70(3):205-9.
Porcher FK. (1992): HIV-infected pregnant women and their infants. Primary health care implications. Nurse Pract 17(11):49-50.

Raphael-Leff J. (1991): Psychological processes of childbearing. London: Chapman and $\mathrm{Hall}$ 310 .

Righard L, Alade MO. (1992): Sucking technique and its effect on success of breastfeeding. Birth 19:185-89.

Victora CG, Tomasi E, Olinto MTA \& Barros FC. (1993): Use of pacifiers and breastfeeding duration. Lancet 341:404-06.

WHO (1987): Special Programme on AIDS Statement: Breastfeeding/breastmilk and human immunodeficiency virus. Geneva:

WHO/UNICEF (1990): Innocenti Declaration on the Protection, Promotion and Support of breastfeeding.

World Alliance for Breastfeeding Action. No date. The Baby-Friendly Hospital Initiative action folder. What can you do to assure your neighbourhood hospital or health faculty is "baby-friendly"

Cheryl NIKODEM, MCur Leonie SCHELKE, MD Lynn ENRAGHT-MOONY, BCur Justus HOFMEYR, M.R.C.O.G. (Professor)

Department of Obstetrics and Gynaecology

Coronation/JG Strijdom HOSPITAL and UNIVERSITY of the WITWATERSRAND 